\title{
PENGELOLAAN KURIKULUM DAN PEMBELAJARAN BERBASIS PESANTREN DI SMP
}

\author{
Yunanto Ari Prabow o \\ SMK Negeri 1 Sragen \\ yariprabowo@yahoo.com
}

\begin{abstract}
This study was to describe the (1) foundation and implementation of curriculumbased learning Pesantren (2) implementation based learning curriculum and Pesantren (3) factors that support and hinder the implementation of the curriculum and learning-based schools. The method in this study used a descriptive approach kualitatif.Teknik data collection are observation, interview, and documentation. To test the validity of the data using a triangulation method, Results of this study were (1) SMP Muhammadiyah Darul Ihsan using curriculum KTSP 2006 is based on official curriculum and uniquely pesantren (2) Study carried out other than in accordance formal school hours learning is also conducted during the students stay in dormitories. (3) The factors supporting that policy right schools, the teachers are professional and complete infrastructure. While inhibiting factors include: conditions of students or students who are less responsible in terms of learning so that they seem still like to play around and learn less than the maximum.
\end{abstract}

Keywords: management, curriculum, learning based pesantren

\begin{abstract}
ABSTRAK
Penelitian ini untuk mendiskripsikan tentang (1) landasan pelaksanaan kurikulum dan pembelajaran berbasis Pesantren (2) pelaksanaan kurikulum dan pembelajaran berbasis Pesantren (3) faktor-faktor yang mendukung dan menghambat pelaksanaan kurikulum dan pembelajaran berbasis pesantren. Metode dalam penelitian ini menggunakan pendekatan deskriptif kualitatif.Teknik pengumpulan data yang digunakan adalah observasi, wawancara, dan dokumentasi. Untuk menguji keabsahan data menggunakan trianggulasi metode,Hasil penelitian ini adalah (1) SMP Darul Ihsan Muhammadiyah menggunakan kurikulum KTSP tahun 2006 berdasarkan kurikulum kedinasan dan kepesantrenan (2) Pembelajaran dilaksanakan selain sesuai jam formal sekolah juga dilakukan pembelajaran selama santri tinggal di asrama. (3) Adapun faktor pendukung yaitu adanya kebijakan sekolah yang tepat, guru yang profesional dan sarana prasarana yang lengkap. Sedangkan faktor penghambat antara
\end{abstract}


lain : Kondisi santri atau siswa yang kurang bertanggung jawab dalam hal belajar sehingga mereka terkesan masih suka main-main dan belajar kurang maksimal.

Kata kunci : pengelolaan , kurikulum, pembelajaran berbasis pesantren

\section{PENDAHULUAN}

Kurikulum adalah seperangkat rencana dan pengaturan mengenai tujuan, isi dan bahan pelajaran serta cara yang digunakan sebagai pedoman penyelenggaraan kegiatan pembelajaran untuk mencapai tujuan pendidikan tertentu. Tujuan tertentu ini meliputi tujuan pendidikan nasional serta kesesuaian dengan kekhasan, kondisi dan potensi daerah, satuan pendidikan dan peserta didik. Oleh sebab itu kurikulum disusun oleh satuan pendidikan untuk memungkinkan penyesuaian program pendidikan dengan kebutuhan dan potensi yang ada di daerah.

Selanjutnya berbicara mengenai bagaimana kurikulum dilaksanakan sama artinya dengan bagaimana proses belajar itu berlangsung. Dengan demikian, pembelajaran sebagai upaya kondisi belajar yang dengan sengaja diatur dan diubah untuk mengembangkan potensi dan kemampuan yang ada dalam diri manuasia. Kemudian menjadi sesuatu yang harus direncanakan dan diatur dalam situasi yang baik dan lebih bermkna.

Menurut Mulyasa (2007:20) bahwa pengelolaan merupakan komponen integral dan tidak dapat dipisahkan dari proses pendidikan secara keseluruhan. Alasannya tanpa manajemen tidak mungkin tujuan pendidikan dapat diwujudkan secara optimal, efektif dan efisien. Pondok pesantren sebagai salah satu lembaga pendidikan Islam yang ada di Indonesia sebenarnya mempunyai peluang dalam menciptakan SDM yang berkualitas dengan catatan pondok pesantren mampu beradaptasi dengan globalisasi yang sedang terjadi dengan tanpa meninggalkan watak kepesantrenannya.

Ada beberapa masyarakat yang mengatakan bahwa lulusan dari pondok pesantren pada era globalisasi saat ini kurang mampu bersaing dengan lembaga penidikan non pesantren dikarenakan pondok pesantren saat ini pengelolaannya kurang baik, baik peran sosialnya di tengah- tengah masyarakat atau lingkungan sekitarnya maupun perannya dalam bidang pendidikan umum. Dengan adanya opini seperti itu budaya yang dimiliki pesantren maupun pemikiran para santri dan pengelola pesantren merupakan penilaian publik yang sebenarnya. Permasalahan sosialisasi para santri yang dimiliki pesantren serta permasalahan dalam hal keilmuan terjadi suatu kesenjangan antara pendidikan di pesantren dengan pendidikan modern saat ini. Dalam rangka pencapaian tujuan pendidikan agar pendidikan itu bisa terarah dan terjadinya suatu aktifitas pembelajaran maka diperlukan sebuah kurikulum yang handal. Dalam pendidikan Islam, kurikulum merupakan suatu alat yang digunakan untuk mencetak generasi yang handal dimasa yang akan datang dan dan menolong mereka menjadi generasi penerus yang membawa nama harum bangsa dan Negara kesuksesan sebuah Negara berada dipundak generasi muda melalui pendidikan. 
Berdasarkan uraian di atas penelitian ini bertujuan untuk : (1) Mendeskripsikan landasan pelaksanaan kurikulum dan pembelajaran berbasis Pesantren di SMP Darul Ihsan Muhammadiyah Sragen. (2) Mendeskripsikan pelaksanaan kurikulum dan pembelajaran berbasis Pesantren di SMP Darul Ihsan Muhammadiyah Sragen. (3) Mendeskripsikan faktorfaktor yang mendukung dan menghambat pelaksanaan kurikulum dan pembelajaran berbasis pesantren di SMP Darul Ihsan Muhammadiyah Sragen.

\section{METODE}

Pendekatan penelitian ini menggunakan jenis penelitian kualitatif. Penelitian kualitatif lebih memberikan tekanan kepada pemahaman dan makna, berkaitan erat dengan nilai-nilai tertentu,lebih menekankan pada proses daripada pengukuran, mendeskripsikan, menafsirkan dan member makna dan tidak cukup dengan penjelasan belaka, dan memanfaatkan multimetode dalam penelitian. (Sutama, 2012:61). Desain dalam penelitian ini peneliti akan melakukan studi kasus yang terkait dengan fenomena proses pengelolaan kurikulum di sekolah berbasis pesantren SMP Darul Ihsan Muhammadiyah Sragen

Nara sumber dalam hal ini yaitu orang yang bisa memberikan informasi lisan tentang sesuatu yang ingin kita ketahui. Adapun nara sumber yang akan digunakan dalam penelitian ini adalah Kepala Sekolah SMP Darul Ihsan Muhammadiyah Sragen, Wakasek Bidang Kurikulum serta Guru mata pelajaran.

Pengumpulan data yang akan dilakukan oleh peneliti dengan menggunakan beberapa teknik pengumpulan data. Adapun teknik pengumpulan data yang digunakan adalah observasi, wawancara ,dan dokumentasi.

Dalam Penelitian ini peneliti akan menggunakan pengecekan keabsahan temuan dengan menggunakan triangulasi metode. Teknik triangulasi ini dilakukan pengecekan terhadap penggunaan metode pengumpulan data, apakah informasi yang dibuat dengan metode interview sama dengan metode observasi, ataukah hasil observasi sesuai dengan informasi yang diberikan ketika di-interview. Dalam penelitian yang peneliti lakukan terutama dalam teknik pengumpulan data baik wawancara maupun observasi pengecekan keabsahan temuan akan menggunakan beberapa metode triangulasi. Dalam penelitian ini peneliti berusaha agar data yang telah dianalisis dapat dipergunakan kebenaran dan keabsahannya melalui cara : pengumpulan data, reduksi data, penyajian data dan verifikasi data.

\section{HASIL DAN PEMBAHASAN}

Landasan pelaksanaan kurikulum di SMP Darul Ihsan Muhammadiyah Sragen berlandaskan pada kepesantrenan. Hal ini dengan tujuan membentuk karakter santri sesuai dengan tujuan yang diharapkan oleh sekolah. Pengelolaan kurikulum disesuaikan dengan kondisi pesantren.

Pembahasan Landasan Pelaksanaan Kurikulum di SMP Darul Ihsan Muhammadiyah Sragen tersebut ada beberapa kesamaan dengan hasil penelitian Jakaria (2012), Contribusi of Madrasah To The Development of The Nation Character. Hasil penelitian ini menunjukkan bahwa madrasah dapat memberikan kontribusi positif dan signifikan terhadap pengembangan karakter bangsa. Pesantren juga mempunyai tujuan untuk pengembangan karakter bangsa sehingga perlu adanya pengelolaan kurikulum yang sesuai dengan kondisi pesantren. 
Bila ditinjau dari kesamaan penelitian tentang landasan pelaksanaan kurikulum dan pembelajaran berbasis pesantren di SMP Darul Ihsan menunjukan bahwa ada kesamaan dalam tujuan kurikulum untuk mengembangkan karakter bangsa melalui kurikulum dan pembelajaran berbasis pesantren. Selain itu dalam penyusunan kurikulum berdasarkan kurikulum kedinasan juga menggunakan kurikulum kepesantrenan yang sesuai dengan kondisi pesantren.

Berdasarkan hasil penelitian dalam pelaksaaan kurikulum dan pembelajaran di SMP Darul Ihsan Muhammadiyah Sragen ada beberapa pembelajaran yang dilaksanakan diluar jam formal pembelajaran. Seperti pembelajaran di pondok tradisional yang menggunakan metode pembelajaran sorogan, bandongan/ wetonan, muhafazah terutama pembelajaran kepesantrenan.

Pembahasan ini mempunyai kesamaan dengan penelitian Bayanfar, (2013). Hasil penelitian ini merupakan upaya untuk menyelidiki kemungkinan peran kurikulum tersembunyi dalam meningkatkan prestasi siswa SMA. Perlu adanya pelatihan bagi guru dengan metode pembelajaran aktif sehingga kurikulum dapat dicapai dan dapat meningkatkan kualitas pendidikan. Bila ditinjau dari kesamaan penelitian tentang pelaksanaan kurikulum dan pembelajaran jelas menunjukkan bahwa ada kesamaan pelaksanaan hidden kurikulum ( kurikulum tersembunyi ) yang dilaksanakan di SMP Darul Ihsan Muhammadiyah Sragen.

Penelitian ini juga ada kesamaan dengan penelitian Lumadi, 2014, Building a Conducive Learning Environment in Dysfunctional School: A Curriculum Development Tool. Hasil penelitian ini bahwa pengembangan kurikulum merupakan alat untuk membangun lingkungan belajar di sekolah yang kondusif. Serta ada kesamaan dengan penelitian Chirwa, 2014, Curriculum Change and Development in Malawi: A Historical Overview. Hasil penelitian ini pemerintah di Malawi perlu melakukan reformasi kurikulum. Kurikulum sebagai alat untuk pengembangan individu belajar melalui proses belajar mengajar.

Kesamaan penelitian ini ditunjukkan dengan adanya kesamaan dalam hal pengembangan kurikulum sesuai dengan kondisi lingkungan belajar pesantren. Dan kurikulum yang dhasilkan sebagai pedoman bagi para pengajar untuk proses belajar mengajar. Wujud kurikulum itu adalah KTSP, silabus, Prota, Promes dan RPP. Hal ini yang dijadikan pedoman pelaksanaan kurikulum dan pembelajaran berbasis pesantren di SMP Darul Ihsan Muhammadiyah Sragen. Untuk kelancaran dalam proses belajar mengajar agar sesuai dengan kurikulum guru/asatid diwajibkan melakukan pengembangan silabus dan menyusun Prota, Promes dan RPP.

Faktor-faktor pendukung Pelaksanaan Kurikulum dan pembelajaran Berbasis Pesantren di SMP Darul Ihsan Muhammadiyah Sragen yaitu (a) Kebijakan Sekolah, kebijakan dalam melakukan penyusunan kurikulum sesuai dengan kondisi sekolah dan menyusun tata tertib di pondok pesantren agar siswa / santri menjadi lebih berkarakter. (b) Guru, guru mampu menjalankan fungsinya karena sangat besar pengaruhnya terhadap cara bertindak dan berbuat dalam menunaikan pekerjaan sehari-hari di kelas dan di masyarakat. Guru yang memahami kedudukan dan fungsinya sebagai pendidik profesional, selalu terdorong untuk tumbuh dan berkembang sebagai perwujudan perasaan dan sikap tidak puas terhadap pendidikan. Persiapan yang harus diikuti, sejalan dengan ilmu pengetahuan dan teknologi (c). Sarana dan Prasarana, tersedianya sarana prasarana yang menunjang dalam pelaksanaan kurikulum dan pembelajaran berbasis pesantren yang meliputi asrama, masjid, ruang kelas, ruang perpustakaan, laboratorium. 
Faktor-faktor penghambat dalam pelaksanaan kurikulum dan pembelajaran adalah kondisi santri atau siswa yang kurang bertanggung jawab dalam hal belajar sehingga mereka terkesan masih suka main-main dan belajar kurang maksimal, kekurangan Asrama maupun tempa tinggal karena kamar dengan jumlah santri kurang seimbang, adanya orangtua yang sering khawatir terhadap anaknya sehingga mempengaruhi anak untuk tidak betah diasrama.

Penelitian ini juga ada kesamaan dengan penelitian Jakaria, 2012, Contribusi of Madrasah To The Development of The Nation Character. Hasil penelitian ini menunjukkan bahwa madrasah dapat memberikan kontribusi positif dan signifikan terhadap pengembangan karakter bangsa. Pesantren juga mempunyai tujuan untuk pengembangan karakter bangsa sehingga perlu adanya pengelolaan kurikulum yang sesuai dengan kondisi pesantren.

Kesamaan dalam penelitian ini adalah untuk pengembangan karakter bangsa melalui pengelolaan kurikulum disesuaikan kondisi pesantren. Untuk mengelola hal tersebut di SMP Darul Ihsan Muhammadiyah Sragen dibuat suatu tata tertib untuk menopang faktor pendukung pelaksanaan kurikulum dan pembelajaran serta untuk menutupi faktor-faktor penghambat dalam pelaksanaan kurikulum yang disesuaikan dengan kondisi pesantren.

\section{SIMPULAN}

Landasan pelaksanaan kurikulum dan pembelajaran berbasis pesantren di SMP Darul Ihsan Muhammadiyah menggunakan kurikulum KTSP tahun 2006 berdasarkan kurikulum kedinasan dan kepesantrenan yang disesuaikan dengan kondisi lingkungan pesantren.

Pelaksanaan kurikulum dan pembelajaran berbasis pesantren di SMP Darul Ihsan Muhammadiyah, pembelajaran dilaksanakan selain sesuai jam formal sekolah juga dilakukan pembelajaran selama santri tinggal di asrama. Selain itu juga direncanakan sejak awal tahun pembelajaran, dilakukan pengawasan serta evaluasi sampai akhir tahun pembelajaran.

Adapun faktor pendukung yaitu (a) adanya Kebijakan Sekolah, dalam melakukan penyusunan kurikulum sesuai dengan kondisi sekolah dan menyusun tata tertib di pondok pesantren agar siswa / santri menjadi lebih berkarakter. (b) Guru, guru mampu menjalankan fungsinya karena sangat besar pengaruhnya terhadap cara bertindak dan berbuat dalam menunaikan pekerjaan sehari-hari di kelas dan di masyarakat. Guru yang memahami kedudukan dan fungsinya sebagai pendidik profesional, selalu terdorong untuk tumbuh dan berkembang sebagai perwujudan perasaan dan sikap tidak puas terhadap pendidikan. Persiapan yang harus diikuti, sejalan dengan ilmu pengetahuan dan teknologi (c). Sarana dan Prasarana, tersedianya sarana prasarana yang menunjang dalam pelaksanaan kurikulum dan pembelajaran berbasis pesantren yang meliputi asrama, masjid, ruang kelas, ruang perpustakaan, laboratorium.

Faktor penghambat antara lain : Kondisi santri atau siswa yang kurang bertanggung jawab dalam hal belajar sehingga mereka terkesan masih suka main-main dan belajar kurang maksimal, kekurangan Asrama maupun tempa tinggal karena kamar dengan jumlah santri kurang seimbang, Adanya orangtua yang sering khawatir terhadap anaknya sehingga mempengaruhi anak untuk tidak betah diasrama. 


\section{DAFTAR PUSTAKA}

Arikunto, S., dan L. Yuliana, 2008, Manajemen Pendidikan. Yogyakarta : Aditya Media bekerjasama dengan FKIP UNY.

Azra, A, 2000 , Pendidikan Islam,Tradisi dan Modernisasi Menuju Melinium Baru Jakarta : Logos Wacana Ilmu.

Bayanfar, F, 2013, The Effect of Hidden Curriculum on Academic Achievement of High School Student, International Research Journal of Applied and Basic Sciences, Vol, 5 (6): 671-681

Chirwa, G, 2014, Curriculum Change and Development in Malawi: A Historical Overview, Mediterranean journal of School Sciences, Vol 5 No. 16: 336-346

Dakir, 2004, Perencanaan Dan Pengembangan Kurikulum. Jakarta: Rineka Cipta.

Departemen Agama RI Direktorat Jendral Kelembagaan Agama Islam, 2003, pondok Pesantren \& Madrasah Diniyah Pertumbuhan dan Perkembangannya, Jakarta.

Dhofier, Z, 2005, Tradisi Pesantren: Studi tentang Pandangan Hidup Kyai. Jakarta: LP3S

Hamalik, O, 2006, Manajemen Pengembangan Kurikulum. Bandung: PT Remaja Rosdakarya. 2007, Dasar-Dasar Pengembangan Kurikulum. Bandung: Remaja Rosdakarya Offset.

Hasan,I, 2009. Pokok-Pokok Materi Statistik 1 (Statistik Deskriptif). Jakarata: PT. Bumi Aksara

Hasbullah, 1996, Kapita Selekta Pendidikan Islam. Jakarta: Raja Grafindo.

Jakaria, M, 2012, Contribusi of Madrasah To The Development of The Nation Character. International Journal of Scientific \& Technology Research, Vol.1: 37-39

Jalaluddin \& Usman, S, 1994, filsafat Pendidikan Islam : Konsep Dan Perkembangan Pemikirannya. Jakarta: PT Raja Grafindo Persada.

Lumadi, MW, 2014, Building a Conducive Learning Environment in Dysfunctional School: A Curriculum Development Tool, Mediterranean journal of School Sciences, Vol 5 No. 6: 319-325

Madjid N, 1997, Bilik-Bilik Pesantren Sebuah Potret Perjalanan. Jakarta: Paramadina.

Maphosa, C, Mudzielwana, NP, Netshifhethe, L, 2014, Curriculum Development in South African Higher Education Institutions Key Considerations. Mediterranean journal of School Sciences, Vol 5 No. 6: 355-367

Moleong, Lexy J, 2010. Metodologi Penelitian Kualitatif. Bandung: Remaja Rosdakarya

Mulyasa, 2007. Kurikulum Tingkat Satuan Pendidikan. Bandung: PT Remaja Rosdakarya.

Nasir, R, 2005, Mencari Tipologi Format Pendidikan Ideal, Pondok Pesantren di Tengah Arus Perubahan. Yogyakarta: Pustaka Pelajar.

Nasution,S. 2001, Asas Asas Kurikulum, Jakata: Bumi Aksara

Sugandi, Akhmad., 2006. Teori Pembelajaran. Semarang: UPT UNNES PERSS

Sugiyono, 2011, Metode Penelitian Pendidikan. Cet. 12. Jakarta: Alfabeta. 
Sukmadinata,NS, 2012, Pengembangan Kurikulum; Teori dan Praktek. Bandung: Remaja Rosdakarya.

Sulton, Mashud, dkk,2004, Manajemen Pondok Pesantren, Jakarta: Diva Pustaka

Susilo,J, Muhammad. 2008. Kurikulum Tingkat Satuan: Yogyakarta Pustaka Pelajar

Sutama, 2012, Metode Penelitian Pendidikan Kuantitatif,Kualitatif, PTK, $R$ \& D. Surakarta: Fairuz Media.

Tabroni, Suprayoga, I, 2001, Metodolgi Penelitian Social Agama, Bandung: Rosada Karya

Undang-Undang Republik Indonesia No. 14 Tahun 2005 Tentang Guru dan Dosen, (Bandung: Citra Umbara, 2006)

Undang-undang Republik Indonesia No. 20 Tahun 2003 Tentang Sistem Pendidikan Nasional Yasmadi, 2002, Modernisasi Pesantren : Kritikan Nurcholis Madjid Terhadap Pendidikan Islam Tradisional, Jakarta : Ciputat Press. 